ALPHA Nº 28 Julio 2009 (209-221)

ISSN 0716-4254

http://alpha.ulagos.cl

\title{
EL ECO DE LA MEMORIA: JUAN GELMAN Y DIBAXU
}

\author{
Nayra Pérez Hernández*
}

En Dibaxu (1994), Juan Gelman, mediante el ejercicio de colocarse debajo del lenguaje, logra vincular la patria de la lengua sefardí y del exilio. A partir de la expulsión de la propia lengua, el poeta argentino hace un viaje hasta la matriz del idioma, llegando a trabajar ese castellano arcaico con su caudal de expulsiones e inclusiones. Esta lengua romance en formación, próxima a sus raíces latinas (ladinas), le permitirá también acercarse a los modos de ver y de decir de la cultura judeo-cristiana. El libro indaga en la lengua y el tiempo: las materias de nuestra humanidad, barro del que estamos hechos.

\section{EL ECO DE LA MEMORIA}

Juan Gelman ha dicho que en Dibaxu se acerca a

\begin{abstract}
Las maravillas y miserias del amor. Sus oscuros fulgores, sus catástrofes. Caminar por el filo de la pérdida. Dar lo que no se tiene. Recibir lo que no se da. El amor a la poesía, a la madre, a la mujer, a los hijos, a los compañeros que cayeron por una esperanza, a la belleza todavía de este mundo. Como cualquier hombre, amé y amo todo eso. Algo de todo eso tal vez tiemble en los poemas que siguen, escritos a lo largo de 40 años. La muerte me enseñó que no se muere de amor. Se vive de amor (1994:15).
\end{abstract}

Se trata, en el fondo, de correr hasta el desierto tras la palabra, allí donde se desdibujan los nombres, para contemplar que la Poesía es un imposible, es arena entre los dedos. También, se trata de cómo habitar en el exilio y llegar a rozar apenas la materia del fuego porque la Poesía es la única avla (1998:76).

Juan Gelman, poeta argentino-poeta judío, nació en Buenos Aires, en 1930. Su padre era un obrero ferroviario - huido de la Rusia zarista en 1905- que recayó en la Argentina, volviendo más tarde a su país con el triunfo de la Revolución del 17; pero, decepcionado con el régimen soviético, y alertado por el destierro de León Trotsky, regresó de nuevo a Argentina. La 


\section{Nayra Pérez Hernández}

madre era hija de un rabino que había sido juez de paz en Odesa, Ucrania. Como informa el poeta

Recuerdo el retrato de mi abuelo, al que nunca conocí, colgado en la pared del dormitorio de mis padres: barbado, quieto en la foto finisecular, con ojos que iban más allá de lo mirado. Y sé que me marcó, mas no sé cómo. Mi madre decía que su padre era más guapo que yo, y que el que se le parecía era mi hijo. Misterios de la herencia (Gelman. Discurso en línea, 2008-05-30).

Desde niño, Juan Gelman creció en un cruce de lenguas. Junto al español, su lengua materna, estaban aquellas extrañas palabras, rusas y hebreas. Por eso, su infancia está hecha de trocitos de lenguaje, y la palabra, más tarde, se convierte en llave contra el olvido, en ranura de la memoria. Su poesía es testimonio, un recordar atravesando la palabra, y reflejo también de toda su experiencia vital, en suma, una obra al compás del existir.

Oponente a cualquier tiranía, Gelman muy pronto se introdujo en los movimientos políticos y sociales de su país. En su juventud formó parte del Partido Comunista, del que más tarde se alejaría, lo que no significó renunciar a su posición, de hecho, su compromiso contra la dictadura de Videla le forzó al exilio.

Dentro de su trayectoria poética se distinguen dos grandes etapas. El primer Gelman, el joven poeta y militante del PC, tradicionalmente se ha ubicado en la que se ha denominado "Generación del 55 o de la ruptura", dentro de la tendencia neo-humanista, por su declarado compromiso humano. Aquí se inscribe su primera gran obra, Gotán (1962), donde explicaba: "el único tema de la Poesía es la Poesía; y por eso la Poesía puede hablar de todo, inclusive de la política o de la sociedad” (Gelman, en Lucas en línea, 200805-27).

El lenguaje de este período es, ante todo, comunicación. Una poesía que se acerca a la de Paul Eluard, "social” que mira también a Vallejo, e introduce con fuerza la irracionalidad y el quebrantamiento del idioma: "Hundir las palabras en la realidad hasta hacerlas delirar con ella”, dice José Galván, heterónimo del autor, en el poemario Hacia el Sur (1982). Asombra la economía verbal alcanzada y el uso de palabras tan sencillas que parecen transparentes. El resultado es una poesía "social” peculiarísima, que nace de la mano de un fino cirujano del idioma, pero que opera sobre la mesa de la realidad.

El Gelman de la segunda etapa, el que nos interesa, es "el poeta judío”, mas no podemos hablar de ruptura, más bien de evolución poética. Es una 
nueva etapa que abre en el exilio, ${ }^{1}$ al que se vio empujado por su compromiso contra las dictaduras militares de los años setenta, hasta despertar de una pesadilla, y encontrarse solo, muy lejos, en medio del desierto. Pero Gelman, aun en ese desierto, se empeña en descubrir un andar hacia la palabra. Y el exilio se hace, lo hace, "puerta” como escribe Cortázar al hablar de la poesía de Juan Gelman

Acaso lo más admirable en su Poesía es su casi impensable ternura allá donde más se justificaría el paroxismo del rechazo y la denuncia, su invocación de tantas sombras desde una voz que desasosiega y arrulla, una permanente caricia de palabras sobre tumbas ignotas (Pérez Cerra en línea, 2008-06-04).

\section{DIBAXU: GÉNESIS DE UN LIBRO}

En el destierro el “yo” se pierde, la salida forzosa de la tierra es desierto también de la propia identidad y surgen las preguntas como quién soy, quién es el que escribe, de quién es la voz que habla, como se aprecia en el poema “El ciego", procedente de Citas y comentarios (1982)

quise olvidarte / pero

mi olvido no te olvida /

puse losas heladas sobre mi corazón

y él late a tu compás /

soy dos $/$

uno come / procura / el otro

cava mis huesos / grita

lo amado / amado está (57).

Gelman desde el desierto emprende una busca de otras voces, para fundirse y confundirse, y se acerca a las voces judías, enlazando así con un pasado y una historia hasta entonces por él ignoradas, pero que son su propia memoria

Mi encuentro de fondo con la cultura judía y hebrea se produjo después, cuando conocí el exilio. Entonces empecé a preguntarme muchas cosas acerca de por qué nos habían derrotado, de las matanzas en la Argentina, la desaparición de seres queridos, la ausencia de uno del país, la ausencia del país de uno, del habla de su gente... Ese sentimiento me

\footnotetext{
${ }^{1}$ Trágicamente es tocado por el dolor: tres miembros de su familia resultan “desaparecidos” (su hijo, cuyo cadáver apareció finalmente, su nuera y el hijo de ambos, que nació en prisión, y del que no sabía siquiera su sexo).
} 


\section{Nayra Pérez Hernández}

llevó a leer por primera vez La Cábala. Y encontré en ella algo acorde con lo que me ocurría, es decir, una visión exiliar de la vida. Encontré esa misma visión en poetas hebreos de los siglos XII, XIII y XIV, sobre todo españoles, italianos y alemanes, y "traduje” algunos de sus textos que reuní en mi libro Com/posiciones. En realidad, lo que hice fue tomar textos y reescribirlos... (Salvador Ale, en línea, 2008-06-05).

En el destierro (París, Barcelona, hasta llegar a México, donde actualmente reside) escribir se convierte en entrar cada día en "lo desconocido" (Escalante, 1994:11). Si el exilio significa hasta la pérdida del "yo", escribir le hace abandonar toda certeza, enfrentarse a esta tarea desde un no-saber, espacio vacío donde engendrar la palabra.

Y así, en su poesía ese vacío se abre y allí confluirán todas las voces: los poetas americanos (Darío, Martí, Whitman, Neruda, Vallejo, Borges, Dalton...); la poesía española (sobre todo Machado); los poetas europeos (los ingleses, a quienes tradujo, pero también Paul Celan, Pessoa). Pero, sobre todo, quiere recoger la voz de los místicos españoles, a quienes había leído de joven, y de quienes ahora hace una lectura nueva, y de la mística hebrea, con la que por primera vez se encuentra. En obras como Com/posiciones (1986) y Citas y comentarios (1982) reelabora la poesía de San Juan de la Cruz, de Santa Teresa o de los místicos hebreos. Recomponer, citar, comentar, dialogar, en definitiva, y poner al poema en la tensión autoría/anonimia, dentro de una concepción de la palabra poética muy cercana a la de Mallarmé y a las teorías de "la desaparición del autor", fruto de un proceso intelectual y espiritual en el que la palabra toma cuerpo más allá de cada identidad, pues, si el "yo" desaparece, la autoría también se pierde. Superar la autodesignación del "yo" y del lenguaje, que niegan la infinita libertad de la palabra, pues, ésta está destinada a ser infinitamente recreada, re-enunciada, libre de circular, lo que explica el propio Gelman en su texto La casa del amor (2006) presentado en el IV Encuentro de Escritores Judíos Latinoamericanos (Buenos Aires, 1982)

A comienzos del siglo XII Yehuda Halevi escribió un famoso poema titulado "La casa del amor" (...) Con excepción del último verso (una clara referencia a la redención del pueblo judío de la esclavitud de Egipto), el poema de Yehuda Halevi, en hebreo, es en realidad una adaptación de un poema de amor árabe, escrito en el siglo VIII. Hace años me atreví a reescribir ese poema de Yehuda Halevi, ya no en relación con el amor o con Jehová, sino con el exilio, el mío. (...) A veces tengo un sueño maravilloso: que alguien vuelva a partir de este poema mío, poema que prolonga la escritura de hace nueve siglos, y que es eco de otra de tres siglos antes. Porque la poesía es infinita y es dado 
sentir su infinitud, por la que hombre y nombres pasan con la fugacidad de un leve resplandor, sellados por el deseo de alimentarse de ella (Gelman, Diálogo en línea, 2008-06-02).

Ya desde Relaciones (1973) Gelman comienza a trazar el mapa poético de toda una década, de su etapa del exilio. Los poemas de esta obra ya componen un discurso descarnado, ardiente, reflejo de épocas turbulentas. Aquí, el recurso más sobresaliente es el de la interrogación, y con la eliminación de signos de puntuación, las respuestas se expresan iguales a la pregunta, pero significando lo contrario o dudando, como en una especie de soliloquio de conciencia analítica, contestataria y, a la vez, cargada de una nostalgia manifiesta en el lenguaje directo, sencillo. Este mecanismo de "preguntas inexistentes", coloca a Gelman en el ángulo de la reflexión, sitio que no abandonará jamás y que se verá reflejado en toda la obra, de aquí en adelante.

En su incesante búsqueda irá agregando otros recursos, como la utilización de barras que establecen ritmos o sentidos. Esto continuará en Hechos, publicado junto con la reedición de Relaciones, como Hechos y narraciones (1980). Hechos es el primer libro del exilio y el lenguaje, aquí, es más áspero, pesimista, un eco del dolor por las muertes de los compañeros, el desarraigo, la melancolía. Se trata, a pesar de todo, de un juego pasional con la lengua, incluso violentándola con la invención de palabras, cambiándolas de género, conjugando sustantivos y adjetivos como verbo. Las palabras fluyen desnudas, sangrantes, dejándose llevar por la fuerza de la tragedia, por el drama del duelo, por la impotencia de la lejanía y la desesperada injusticia de no saber. En Hechos, las palabras develan uno a uno todos los sueños rotos de una generación entera, de un país ensangrentado.

En Citas y comentarios (1982), la construcción de los poemas se muestra más cerrada, pero es perfecta en su forma. Cada uno nace de frases o de imágenes halladas en otros textos, de Santa Teresa, San Juan, Le Pera, Baudelaire y Van Gogh, entre otros, para armar un bello canto de amor a la patria lejana.

Hacia el Sur y otros poemas (1985) es un libro de composiciones muy extensas, donde se mezclan temas, incluso dentro de cada uno de ellas, pero teniendo como base siempre, el tema político. Los poemas de amor de Anunciaciones y otras fábulas (2001) destilan un desamparo y una soledad pasmosa: imágenes contundentes, breves, concretas, signos de exclamación que, reemplazando las preguntas, se hacen oír en gritos.

En Salarios del impío (1998), se entreteje un juego de pequeños gestos que pasan por el tema del exilio, el amor, la soledad, el miedo y la muerte, apenas como un roce, dejándolos entrever tenuemente, pero con una fuerza 


\section{Nayra Pérez Hernández}

conceptual que permite adivinarlos claramente. Ideas que no terminan de completarse, una especie de cuadro donde todas las figuras están constituidas por líneas abiertas, en fuga, saliendo y entrando en él. Un nuevo encuentro en la misteriosa aventura del lenguaje, un libro que se presenta caprichoso e intenta mostrar "la otra cara de la moneda".

Tras este comienzo en su andadura exiliar física y poética, el siguiente paso será Dibaxu (1994), donde recoge 29 poemas compuestos entre 1983 y 1985, y escritos en sefardí, en ladino, la lengua de los judíos españoles exiliados por los Reyes Católicos en el siglo XV. Este poemario —según Gelman- de algún modo significa la culminación de su aventura hacia el mundo judío: "Como si la soledad extrema del exilio me empujara a buscar raíces en la lengua, las más profundas y exiliadas de la lengua” (1998:51).

El descubrimiento de los textos de Clarisse Nikoïdski, novelista en francés y poeta en sefardí, desvelan y despiertan en Gelman una necesidad que dice en mí dormía, sorda, dispuesta a despertar ¿Qué necesidad? ¿Por qué dormía? ¿Por qué sorda? En cambio, sé que la sintaxis sefardí me devolvió un candor perdido, y sus diminutivos una ternura de otros tiempos que está viva, y por eso, llena de consuelo. Escribir en ladino, lengua casi perdida, idioma de no-estar, significa una busca de arraigo, perderse-encontrarse en una lengua ajena y propia: partindu di tu ladu / discuvro / il nuevu mundo / di tu ladu... (Gelman, Diálogo en línea. 2008-06-02). Explica el poeta

La lengua es mucho más que una cosmovisión. Tiene un inconsciente, depósito de siglos (...) matriz que aún nos contiene y contenemos, aún nos alimenta y alimentamos. (...) Pasamos del vientre materno a la lengua materna, de un matriz material a otra espiritual (...) las lenguas del exilio desembocan en el gran río del idioma de los argentinos (Gelman, Diálogo en línea. 2008-06-02).

Para Gelman, la memoria es uno de los pilares de la poesía

¿No se siente acaso al hablar y sobre todo al escribir las irrigaciones de esa matriz que nos hace la boca, las oscuridades, aguas, navegaciones, su latir secreto y circular, la inminencia de otro mundo detrás de esa pared transparente de nadas, mundo que atisbamos sin tocar, cuya lejana cercanía nos toca como presente ausencia que nos habla, que nos hace hablados por "aquello" que para San Juan de la Cruz es Dios? (Gelman, en Salvador Ale en línea. 2008-06-05).

Y es la lengua, también, la memoria colectiva de los pueblos, lo que, trasladado al terreno social, lleva al poeta a decir que "una nación que pretende construir sobre un olvido, estalla antes o después” (Gelman, 
Discurso en línea. 2008-05-30). Etimológicamente, el antónimo de la palabra "olvido" es "verdad". Lengua = memoria = verdad, por lo que actualmente lo encontramos comprometido, en lucha contra el olvido en que vive su país. Tras el espanto vivido por Argentina en los setenta y ochenta (dictadura, censura, tortura, persecución, exilio), con todas sus consecuencias, que han podido recordar al fantasma nazi, y tras la pesadilla personal de Gelman, tan parecida a la de tantos compatriotas, se le ha hecho muchas veces aquella vieja pregunta: “¿Se puede escribir poesía después de los campos de concentración?” Y responde

Creo que es una pregunta mal formulada. La cuestión es si es posible escribir poesía de otro modo. Paul Celan respondió escribiendo en el idioma del enemigo. (...) A la poesía no la va a matar nadie. Hace 3.000 años los chinos empezaron a recoger una tradición oral, y hay poemas de esa tradición que son plenamente actuales. La poesía ha pervivido todas las catástrofes a lo largo de la historia, y seguirá haciéndolo (Gelman, en Corti en línea. 2008-05-28).

Su trabajo y su obra es, simplemente, su respuesta. Dibaxu es acercamiento, diálogo y recreación de la mística española y judía, aunque en un misticismo no religioso. Gelman emprende un movimiento de salida de uno mismo y búsqueda, no ya de Dios, sino de "el otro". Toma del misticismo la experiencia del éxtasis, la "salida hacia” el amor humano, la amistad, la solidaridad en el dolor; encontrando, además, otro punto de contacto con la experiencia poética de los grandes místicos en la propia escritura: el éxtasis se cumple en la escritura, pues la Poesía es el Imposible: un avla qui va dizer / una palabra que está por decir (1998:98-99). Por eso, "lo que puede hacerse es escribir poemas”, dice Gelman (Discurso en línea, 2008-05-30) a pesar de los nuevos campos de concentración de nuestros días, contra ellos, por la vida. Esta obsesión por encontrar respuestas que, a la vez, vayan produciendo una abstracción, se verá continuada con Incompletamente (1997), por medio de técnicas que derivan del soneto.

\section{DIBAXU DEL LENGUAJE: PARA PODER DECIR-SER}

El ejercicio que Juan Gelman opera sobre el lenguaje en Dibaxu va más allá de la elección del ladino como idioma de expresión. Aparte del ecodiálogo con otros escritores, de todos los tiempos, estilos y orígenes —que ya iniciara en obras anteriores, y que aún se aprecia en ella- debemos hablar de auténtica invención y actualización del lenguaje, batalla con la palabra.

Aparte del exilio, físico y espiritual, que lo arroja "afuera”, Gelman es conciente de la naturaleza exiliar de la propia Poesía y de la condición del 


\section{Nayra Pérez Hernández}

poeta. Pareciera recordar a Huidobro, con su retadora frase "el poeta no puede escribir en la lengua materna”. Por tanto, ha de inventarse una propia, como se aprecia en la obra huidobriana. Pero lo que hace Gelman no va en el sentido de actualizar la lengua sefardí, ni siquiera. En el entendido de que Gelman es un poeta que está hablando desde un exilio doble, nada más natural que hacer uso de una lengua extinta: hablada por los judíos antes de la invasión mora. Gelman, descendiente de judíos y hermanado, a la vez, con todos los que alguna vez han sido perseguidos, logra proponer una serie de poemas que rescatan la música del sefardí, tan simple, tan claro, como un español de agua, donde lo más grave se dice cantando

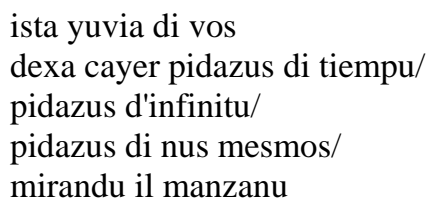

(Salarios, XXV:100)

Palabra exiliada, palabra de polvo, más, "polvo enamorado de la palabra”, Gelman rescata a la vez que reinventa, a su modo, al español "actual”, logrando una capacidad expresiva que sorprende por sus mínimos recursos, por prescindir del sesgo misterioso que acompaña la lectura de su obra en general, por lograr una escritura cristalina. Gelman se auto-exilia de su lengua materna para contarnos cómo ve el mundo un hombre desde el revés del habla, donde cabe todavía alguna esperanza, donde el mundo guarde tal vez su dolor, pero en notas diferentes.

¿Cómo es esa lengua que construye para intentar nombrarse, él, el poeta, el exiliado? ¿Cómo cantar el fracaso y al mismo tiempo la esperanza? No hay otro remedio que colocarse Dibaxu (debajo), como una búsqueda desesperada de lo que está en lo más recóndito de la lengua con la que habla y trabaja.

Entre Salarios del impío (1993) e Incompletamente (1997) aparece la lírica extrema de Dibaxu (1994). En su presentación, Gelman sugiere leer en alta voz las dos versiones de cada poema, en sefardí y en castellano moderno. La idea de rareza se impone para iniciar una descripción de la obra, porque su título es Dibaxu, es decir, porque ya desde la portada resulta inadecuado o insuficiente ubicarlo en el ámbito de la "lengua española". Se trata, en realidad, de 29 poemas breves que se repiten uno a uno en dos lenguas: en castellano actual sobre la página impar, y antes, sobre la página par, en sefardí o ladino, el dialecto de los judíos españoles formado y usado, sobre todo, durante la Edad Media. El propio autor explica esta necesidad en Salarios 
....acompaño los textos en castellano actual no por desconfianza en la inteligencia del lector. A quien ruego que los lea en voz alta en un castellano y en el otro para escuchar, tal vez, entre los dos sonidos, algo del tiempo que tiembla y que nos da pasado desde el Cid (1998:51).

Los poemas de Dibaxu son poemas de amor. Pero además, Dibaxu (“debajo"), con ese juego de autotraducción, indaga en lo que Gelman ha llamado "el sustrato" de la lengua y, son por tanto, poemas sobre el tiempo, sobre el paso del tiempo y sobre lo que en nuestra propia lengua — es decir, en el interior más íntimo de nuestra subjetividad y de nuestra historia - ha quedado soterrado pero sigue dialogando, en sordina, con nuestro presente. En este sentido, puede decirse que el libro cierra o culmina toda una etapa de la obra poética de Gelman, lo que podríamos llamar en cierto sentido su obra de madurez, signada por la problemática del exilio forzado y sus consecuencias. Pues, esa experiencia colectiva de expulsión, persecución y desarraigo toma en su trabajo literario la forma de una indagación minuciosa sobre historia de las formas del idioma.

Este modo de vérselas con la cultura a través de una exploración desregulada de la lengua tiene un natural efecto creciente que podríamos calificar como político o, mejor, ideológico. Las preguntas que se leen en los versos de Gelman son consecuencia de esa desregulación del idioma, es decir, de una escritura que ignora el orden del mundo que se nos impone mediante el orden del discurso (o sea, mediante el sentido común cultural). En relación con Dibaxu, Enrique Fofani ha señalado

Lo que sorprende en el poeta ladino —el poeta lenguaraz - es la familiaridad con la lengua que adopta. Pero esta experiencia extraterritorial combate la figura romántica del escritor enraizado, del genio vernáculo que se siente llamado a construir una nación precisamente a partir de la interpretación ideológica del pasado (Hurtado en línea, 2008:05-25).

Por eso, en el sentido en que Fofani usa aquí el término "ideología”, puede decirse que los juegos poéticos con la lengua que se despliegan en la obra de Gelman producen efectos imaginarios y semánticos contraideológicos. Nos extrañan, nos vuelven, por un momento, extranjeros de nuestra propia lengua, de nosotros mismos, porque desarticulan las fronteras de nuestro mundo, de nuestros modos de ver el mundo y, así, amplifican y enriquecen las posibilidades de nuestra experiencia.

En Dibaxu, la vinculación de la patria con la lengua y del exilio con la expulsión de la propia lengua lleva a que Gelman remonte ese río hasta la matriz del idioma, ese castellano arcaico que es el sefaradí, que lleva puesta 


\section{Nayra Pérez Hernández}

su huella de expulsiones y también un caudal de inclusiones. Esa lengua romance en formación, próxima a sus raíces latinas (ladinas), arrastra los modos de ver y de decir de la cultura judeo-cristiana. El libro indaga la lengua y el tiempo, acaso las materias de nuestra humanidad.

El candor del ladino presta a los poemas su ruralidad primitiva: unas pocas palabras, tan sencillas y antiguas como el sol, la lluvia, el pájaro, la hoja, instauran el amor, inabarcable para el lenguaje, pero sugerido en los silencios del texto. Con un fuerte lirismo, estas breves composiciones crean, por contraste, la plenitud y la carencia. Detrás vibra el lirismo profundo y diáfano de alguna poesía tradicional española, según señala el propio Gelman en Salarios

Sé que la sintaxis sefardí me devolvió un candor perdido y sus diminutivos, una ternura que está viva y, por eso, llena de consuelo. Quizás este libro apenas sea una reflexión sobre el lenguaje desde su lugar más calcinado, la poesía (1998:51).

El cuerpo del poema, vulnerado por su propio lenguaje, conforma en sí una dicotomía que sólo le es dado descifrar al lector capaz de desafiar el filo de los arrecifes y la densidad coralina. En Juan Gelman el esqueleto del texto, si atendemos a lo visual, es decir, a la forma en que el poema se mantiene de pie, a su configuración física como tal, pareciera más bien una cosa enclenque, medio quebradiza, sin puntuación y sin mayúsculas en muchas de sus partes y apoyada por una serie de cortes que hacen las veces de andamios o soportes. Son figuras frágiles configuradas en pequeñas manchas de signos en movimiento que bien pueden ser "hormigas, sangre delirante o estrechos esteros de palabras corriendo en busca de su río”, como expresa Gelman en Salarios (13).

amarte es esto:

una palabra que está por decir/

un arbolito sin hojas

que da sombra/

amarti es istu:

un aula qui va a dizer/

un arvulicu sin folyas

qui da solombra/

(XXIV:98-99).

Se trataría de una poética del despojo que se construye a partir de negaciones inesperadas y de negaciones montadas encima de otras sutiles negaciones, lo cual no excluye, empero, la afirmación infinitesimal, la casi 
invisible, la que milagrosamente nos sostiene en el mundo. Quizá la carne es menos que una brizna de hierba. Quizá la carne es menos que una brizna llevada al azar por el aire, un puñado de átomos inquietos ¿Quién fija las medidas? Puede ser, igual, que la existencia no sea sino una historia de un destierro que no termina nunca. A la hora de la noche más negra, sin embargo, cuando más derrotado está, cuando más en sus huesos, el poeta sigue triunfando. Sólo él, a nombre de todos, puede decirle gloriosamente a una mujer, en una suerte de triunfo inconmensurable, unos versos como éstos

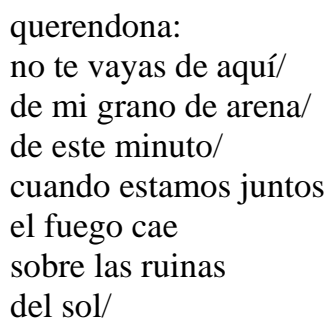

(Salarios, XIX:89).

Universidad de Las Palmas de Gran Canaria* Facultad de Filología Española, Clásica y Árabe Res. c/Virgen del Pilar $N^{\circ} 24,9^{\circ}$ B. CP. 35.012, Las Palmas de Gran Canaria

Islas Canarias (España) nayraperez@yahoo.es

\section{BIBLIOGRAFÍA}

BOCCANERA, Jorge. "La experiencia del exilio: entrevista con Juan Gelman. Clandestino en el país”. Brecha, el 3 de septiembre de 1999. http://sololiteratura.com/php/autor.php?id=16\&seccion=4 Consultado: 2008-05-28.

CHIROM, Daniel. “Una poesía maravillosa y cierta”, en El Jabalí No 18, 8 de septiembre de 2008. http.//www.poesíaeljabalí.com.ar/18contenidos/2cont18_gelman_premi o.htm. Consultado: 2008-05-27.

CLARÍN. Entrevista "Una batalla de palabras", domingo 17 de septiembre de 2000. www.sololiteratura.com/gel/gelentrevistas.htm. Consultado: 2008-06-07.

CORTI, Héctor. "Una vida con ética y compromiso", 9 de marzo de 2006. http://www.elortiba.org/gelman1.html. Consultado: 2008-05-28. 
Nayra Pérez Hernández

DALMARONI, Miguel. "Historias que hacen Historia, Juan Gelman: las extrañas fronteras del mundo", 19 de junio de 1997.

http://psiconet.com/tiempo/historias/gelman.htm. Consultado: 2008-0607.

ESCALANTE, Evodio. "Prólogo. Por los goznes Gelman (Corte) de nuestra gracia”, en Dibaxu (1983-1985). Buenos Aires: Seix Barral, 1994. (reeditado 1994).

FLEMING, Leonor. “Juan Gelman. Poesía sefardita rioplatense”. cvc.cervantes.es/artes/sefarad/memoria/poesia.htm.

Consultado: 2008-05-20.

GELMAN, Juan. “Diálogo amoroso de culturas”, 8 de octubre de 2006. http://letrasytripas.blogspot.com/2006/10/dilogo-amoroso-deculturas.html. Consultado: 2008-06-02.

------- La casa del amor, en "Diálogo amoroso de las culturas", 8 de octubre de 2006. http://letrasytripas.blogspost.com/2006/10/dialogo-amorosode-culturas.html. Consultado: 2008-06-02.

------- "Discurso de Juan Gelman en la entrega del Premio Cervantes". www.pagina12.com.ar/diario/elpais/subnotas/103008-32447-2008-0424.html

------- Anunciaciones y otras fábulas. Buenos Aires: Seix Barral, 2001.

------ Salarios del impío y otros poemas. Madrid: Visor, 1998.

------- Incompletamente. Buenos Aires: Seix Barral, 1997.

------- Dibaxu (1983-1985). Buenos Aires: Seix Barral, 1994. (reeditado 1994).

------ Com/posiciones. Barcelona: Mall, 1986.

------ Hacia el Sur y otros poemas. Buenos Aires: Espasa Calpe, 1985.

------- Citas y comentarios. Madrid: Visor, 1982.

------- Hechos y narraciones. Barcelona: Lumen, 1980.

------ Relaciones. Buenos Aires: La Rosa Blindada, 1973.

GUTIÉRREZ, Rosana. "Juan Gelman. Memoria de la sombra de la memoria”, en Babab Revista de Cultura, N ${ }^{\circ}$ 5, noviembre 2000.

HUIDOBRO, Vicente. Prefacio de Altazor. http://www.avantel.net/ eoropesa/html/poesia/vhuidobro1.html. Consultado: 2008-06-07.

HURTADO, Eduardo. "Epílogo. Contra la pura muerte”, en Dibaxu (19831985). Buenos Aires: Seix Barral, 1994 (reeditado 1994).

IBÁÑEZ QUINTANA, Jaime. “Juan Gelman, Premio Cervantes 2007”, 29 de noviembre de 2007.

www.clarin.com/diario/2007/11/29/um/m-01553084.htm. 
Consultado: 2008-05-28.

"Poesía de exilio de Juan Gelman - Dibaxu, 1994”.

www.wikilearning.com/monografia/poesia_de_exilio_de_juan_gelmanDibaxu_1994/18359-12. Consultado: 2008-05-20.

LUCAS, Kintto. "Poesía es una realidad que puede golpear o acariciar”, 27 de noviembre 2001.

www.sololiteratura.com/gel/gelentrpoesiaes.htm.

Consultado: 2008-05-22.

PÉREZ CERRA, Luis Antonio. “Juan Gelman, el poeta militante argentino”. http://perezcerra.blogspot.com/2007/11/juan-gelman-el-poetamilitante.html. Consultado: 2008-06-04.

PETRICH, Blanche. Entrevista a Juan Gelman, poeta argentino: "Hay que seguir derribando los muros”, en La Jornada (México), 10 de noviembre de 1999.

http://sololiteratura.com/php/docinterno.php?cat=miscelanea\&doc=306. Consultado: 2008-06-02.

RAYA, Javier. "Invención y actualización de una lengua en Dibaxu de Juan Gelman”. 2007-04-03.

http://espanol.agonia.net/index.php/article/240125/index.html.

Consultado: 2008-06-04.

SALVADOR ALE, Pedro. "Juan Gelman: la fe poética”, entrevista publicada en Periódico de Poesía, N 11. México: 1995.

SILBERMAN DE CYWINER, María E. "La poesía amorosa sefardí", 15 de julio de 2007.

http://www.milimcultural.com.ar/newsletter/milim031.htm. Consultado: 2008-06-01.

YANES, Juan. "Darle el último toque a una obra, es decir, quemarla”, 11 de diciembre de 2007.

www.letrasdechile.cl/mambo/index.php?option=com_frontpage\&Itemi

$\mathrm{d}=1$ \&limit=17\&limitstart=221.

Consultado: 2008-05-25. 